\title{
Neuroscience as a Basis for Innovations in Education
}

\author{
Jana Trníková - Erich Petlák
}

\begin{abstract}
We live in a time in which a "revolution" in education is occurring. Through brain research and technology, we have unlocked many of the reasons why some children experience so much difficulty in learning. We know more about effective teaching practices than at any other time in history. Through technological advances, we have a whole world as our resource base. In addition, teachers are finally being empowered to make choices that affect their classrooms.

Keywords: brain, brain-based teaching, neuroscience, neurodidactics, innovations, brain-based learning principles.
\end{abstract}

\section{Introduction}

Hundreds, maybe thousands of books about the human brain have been published during the past 12 to 15 years, probably more than in many decades before. Without question, teachers want to learn as much as possible about how the brain functions in the limited time available to them for personal study. After all, teachers are responsible for what happens to somewhere around 20 young brains every day at school. A major role of teachers is to know enough about brain research and to help pupils develop into the best that they can possibly become.

Learning first comes in through our senses. As we explore and experience our material world, initial sensory patterns are laid down on elaborative nerve networks. These initial sensory patterns become our reference points and give us the context for all learning, thought, and creativity. From this sensory base we add emotions and movements in our life-long learning.

Each pupil brings a unique personal neural history to school every day that gives teachers quite a challenge as they try to customize learning for each pupil. This uniqueness makes a strong case for legitimacy of different learning styles, a variety of learning strategies, multiple intelligences, and the role of appropriate choice. So while the history of a pupil (and his or her brain) does influence learning, it does not determine the learning. Even in the moment, it is how a pupil feels about the learning that plays as big a part as anything. When pupils feel safe, exploratory, challenged, supported, and confident, miracles often happen. These miracles are the result of the triumph of environment over genetic makeup in the pupil's brains. Scientists now know that our genes are susceptible to environmental input.

Innovations coming into the attention of teachers also in Slovakia are known as neurodidactics, neuropedagogy or brain-based learning. These three terms are linked by the common base neuroscience, as a science about internal structure and functions of the brain which connects results of the research based on medical (neurological field) and other disciplines, creating multidisciplinary approach to the educational process and its other elements.

\footnotetext{
* Jana Trníková, Constantine the Philosopher University, Nitra, Slovakia; jtrnikova@ukf.sk Erich Petlák, Dubnica Technological Institute, Dubnica nad Váhom, Slovakia; petlak@dti.sk
} 


\section{Theoretical analysis of the terms neurodidactics, neuropedagogy, and other related terms}

In the 1980s, brain-based education finally emerged as a whole new field based on what we were learning about the brain and how it might affect education. At least a part of the driving force behind related new fields of neurobiology (neurology and biology) and cognitive neuroscience (cognitive science and neuroscience) was technology, drugs and biomarkers. New technology provided us with imaging tools to look inside the brain, such as the magnetic resonance imaging (MRI), functional MRI (fMRI), and positron-emission tomography (PET). For the first time in history, we could analyze the brain while its owner was still alive (Jensen, 2008a, p. 3).

In 1983 a new paradigm established connections between brain functions and traditional educational practice. In a groundbreaking book "Human Brain and Human Learning" L. Hart (1983) argued that cognitive processes were significantly impaired by classroom threat. Because if we ignore how our pupils' brains work, we will risk pupils' success. Many have tied brain function to either new models of thinking, as H. Gardner (1983) did in Frames of Mind: The Theory of Multiple Intelligences, or classroom pedagogy, as R. Caine and G. Caine (1991) did in Making Connections: Teaching and the Human Brain.

The development mentioned above as related to the USA had a great influence on the progress in Europe. Mind, Brain, and Education (MBE) science began as a cross-disciplinary venture between cognitive neuroscience and developmental psychology, but then it reached further beyond these parameters to integrate education via educational psychology and educational neuroscience (Figure 1) (Tokuhama-Espinosa, 2010).

Figure 1 MBE Science as a Multidisciplinary Field (Tokuhama-Espinosa, 2010)

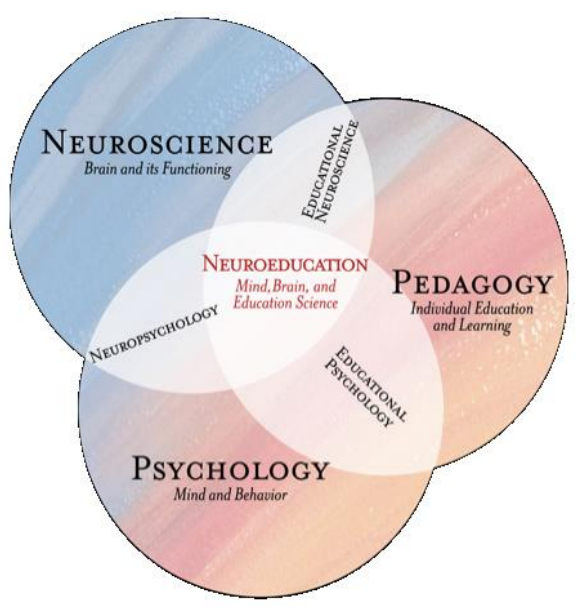

In 1988 G. Preiss, professor of didactics at the University of Fribourg, a specialist in early childhood mathematics education for youngest between two and a half and seven years, has pioneered programs that combined neurological research with math education and are based on a holistic approach to education. He propounded the introduction of an autonomous subject based on brain research and pedagogy that he called neurodidactics. According to this new discipline, school pedagogy and general didactics must attach more importance to the fact that learning lies in brain processes and that cognitive results keep up with the development of a child's brain. By taking this into account, one may say that neurodidactics studies the conditions under which human learning can be optimized to its highest level. 


\section{Acta Technologica Dubnicae \\ volume 2, 2012, issue 2}

Neurodidactics is an interface between neuroscience, didactics, pedagogy and psychology. It tries to work out principles and proposals for effective learning based on the findings of brain-research. A new branch of education theory appeared that attempts to relate teaching strategies and learning modalities to the hard facts of brain research. This new learning theory called "neurodidactics" or "neuropedagogy" referring to brain-based learning came under debate in Europe recently (Caspary, 2006; Herrmann, 2006; Preiss, 1998; Spitzer, 2006).

Brain-based education is related with the terms mentioned above. Brain-based education is, according to E. Jensen (2008a, p. 4), best understood in three words: engagement, strategies, and principles. Brain-based education is the engagement of strategies based on principles derived from understanding of the brain. It is not based on strategies given to us from neuroscientists. That is not appropriate. The author further states that brain-based learning in accordance with the way the brain is naturally designed to learn. It is a multidisciplinary approach that is built on this fundamental question: What is good for the brain? It crosses and draws from multiple disciplines, such as chemistry, neurology, psychology, sociology, genetics, biology, and computational neurobiology.

It is also a way of thinking about learning. It is a way of thinking about teacher's work. It is not a discipline on its own, nor is it a prescribed format or dogma. In fact, a "formula" for it would be in direct opposition to the principles of brain-based learning.

Although a brain-based approach does not provide a recipe for us to follow, it does encourage us to consider the nature of the brain in our decision making. By using what we know about the brain, we can make better decisions and reach more learners, more often, and with fewer misses. Quite simply, it is learning with the brain in mind.

Brain-based education considers how the brain learns best. The brain does not learn on demand by a school's rigid, inflexible schedule. It has its own rhythms. If we want to maximize learning, we first need to discover how nature's engine runs. This singular realization alone has fueled a massive and urgent movement worldwide to redesign learning. What we thought was critical in the past, may not, in fact, be very important at all.

We can state that the terms neurodidactics, neuropedagogy, brain-based or brain compatible learning and teaching are similar in their definitions, because they emphasize brain and the necessity to have knowledge about it, which plays an important role in education across the world. This approach deals with "brain-based" principles and strategies and the impact of neuroscientific knowledge on pedagogy and didactics. These terms have defenders as well as opponents. We can follow the various attitudes on the internet often criticized because of differences in the used terms.

\section{Overview of brains anatomical structure and learning process}

Nature's biological imperative is simple: no intelligence or ability will unfold until, or unless, it is given the appropriate model of environment. From a biological perspective, it is important to realize that the human brain, like the immune system, is designated solely for survival. Pupils will do what they need to do to survive in the "schoolyard jungle". The "negative" behaviors they learn (put-downs, deceit, attacking, avoidance, and peer pressure) are to be expected as long as pupils perceive that their survival is at stake.

As M. L. Slavkin (2004, p. 38) says, brain is "not only the control center of the entire human body, organizing our behaviors and biological functions, but it is also the seat of our humanity. It defines who we are, how we act, and the nature of our species." 


\section{Acta Technologica Dubnicae \\ volume 2, 2012, issue 2}

To understand pupil's behavior and activity at school, we must understand how the brain works. And to understand how the brain works, we must first have at least some basic understanding of the cells that carry messages back and forth in the brain and throughout the rest of the body.

The brain is the most complex organ we possess. Cell counts vary widely among humans, but generally speaking, a person's brain contains between 50 billion and 100 billion (100.000.000.000) neurons. For the sake of comparison, consider that a monkey has about 10 percent of that, a mouse has about 5 million brain cells, and a fruit fly has about 100000 . Individual cells do not make us smart; it is their connections that do. When linked together, the number of connections our brain cells can make is estimated to be from 100 trillion to as much as 10 followed by millions of zeroes (more than the estimated number of atoms in the known universe).

A neuron is a basic structural and processing unit of the nervous system. It has three primary functional areas: the cell body (soma), the outbound projection (axon), and the inbound "feeder systems" (dendrites). Its structure and properties allow it to conduct signals by taking advantage of the electrical charge across its cell membrane. Neurons cannot be seen with the naked eye and come in many sizes and structures.

Figure 2 Axon and dendrite model (Jensen, 2008a, p. 14)

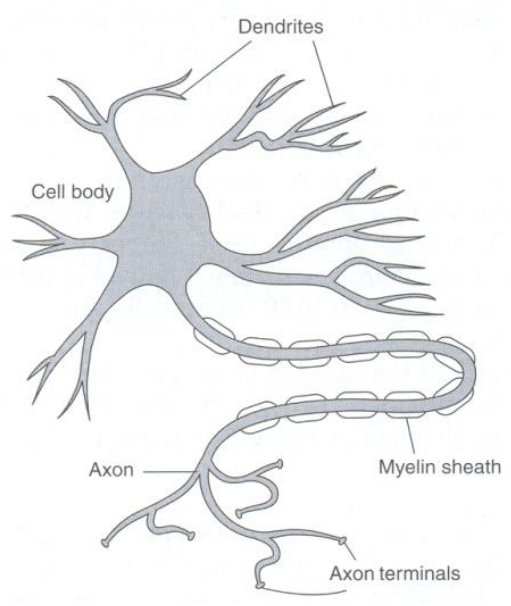

A normally functioning neuron continuously fires, integrates, and generates information across microscopic gaps called synapses (a term derived from the Latin word that means "to grasp"), thereby linking one cell to another. No neuron is an end point in itself. Rather, each acts as a conduit for information. Always busy, neurons generate a hotbed of activity. In fact, a single neuron may connect with 1000 to 10000 other cells. As a rule, the more connections your cells make the better.

Dendrites are branchlike extensions protruding from a cell body. They are receivers of the input that gets passed along from neurons to cells (Figure 2). The sum of all the synaptic reactions arriving from the dendrites to the cell body at any given moment determines whether that cell will, in fact, fire. In other words, learning involves groups or networks of neurons. There is threshold to reach, too; the cell needs enough activation to fire, or it will remain dormant and no memory will be activated.

Although the cell body has the capacity to move, most adult neurons stay put and simply extend their single axon outward. Some axonal migration is genetically programmed, and some is a result of environmental stimulation. Axons normally talk only to dendrites and dendrites normally talk only to 


\section{Acta Technologica Dubnicae \\ volume 2, 2012, issue 2}

axons. When an axon meets up with a dendrite from a neighboring cell, the "eureka" moment of the learning process occurs.

To connect with thousands of other cells, the axon repeatedly subdivides itself and branches out. Neurons serve to pass along information that flows in one direction only. The dendrites receive input from other axons and transmit the information to their cell body. Then the information moves out to the axon that communicates it to another cell through dendritic branches. An electrical impulse travels down the axon where it triggers the release of neurotransmitters into the synaptic gap. In the span of a microsecond, the chemicals travel across the gap (about 50 microns) and are absorbed into receptor sites on the surface of the receiving dendrite.

Neurotransmitters influence the synaptic reactions and result in learning impairment, enhancement, or no effect. For example, a low level of the stress hormone cortisol during a learning session has no known effect. Moderate levels, however, enhance synaptic efficiency, and high levels impair learning. On the other hand, the neurotransmitter noradrenaline seems to have the opposite effect. Low levels have no effect, but high levels enhance learning and memory. Progesterone, testosterone, and dozens of other hormones also impact learning. For example, testosterone seems to support spatial learning, but only in moderate levels. A teacher can influence some neurotransmitters (e.g., adrenaline is increased by the type of risk, urgency, and excitement that can happen in a classroom competition), but others are not easily modified (e.g., glutamate seems impervious to our behaviors).

\section{$4 \quad$ How do we and our brain learn?}

Learning is a form of neural plasticity that changes behavior by remodeling neural connections. Specialized neural mechanisms have evolved to make the most of this capability. Researches have long believed that to understand learning as a physiological process they would have to figure out what happens at the level of the neuron and, particularly, at the synapse. Since its discovery three decades ago, long term potentiation has been the best candidate for explaining the neural changes that occur during learning (Garrett, 2009, p. 371).

The brain stores a tremendous amount of information, but information that is merely stored is useless. It must be available, not just when it is being recalled into awareness, but when the brain needs it for carrying out a task. Working memory provides a temporary "register" for information when it is being used (Garrett, 2009, p. 370).

At the most general level, the brain processes for learning are deceptively simple (Figure 3). Input to the brain arrives from the five senses or is generated internally through imagination or reflection. This input is initially processed in the thalamus, the "server" or central switching area of the brain. Simultaneously, it is routed to other specific areas for further processing because time is of the essence. Visual information is routed to the occipital lobe, language to the temporal lobe, and so on.

The brain forms a rough sensory impression of the incoming data. If any of the data are threatening or suspicious, the amygdala (the 'uncertainty' activator) is activated. It will jump - start the rest of the sympathetic nervous system - the part of the nervous system that helps us deal with emergencies - and enable a quick response (Jensen, E., 2008b, p. 16).

Typically, however, the frontal lobes hold much of the new data in short-term memory for 5 to 20 seconds. Most of the new information is filtered, dismissed, and never gets stored. It may be irrelevant, trivial, or not compelling enough. If it is worth a second consideration, new explicit learning is routed to and held in the hippocampus, two crescent-shaped structured in the midbrain area. There the information is processed further to determine its value. 


\section{Acta Technologica Dubnicae \\ volume 2, 2012, issue 2}

Figure 3 How the brain learns new content (Jensen, 2008a, p. 11)

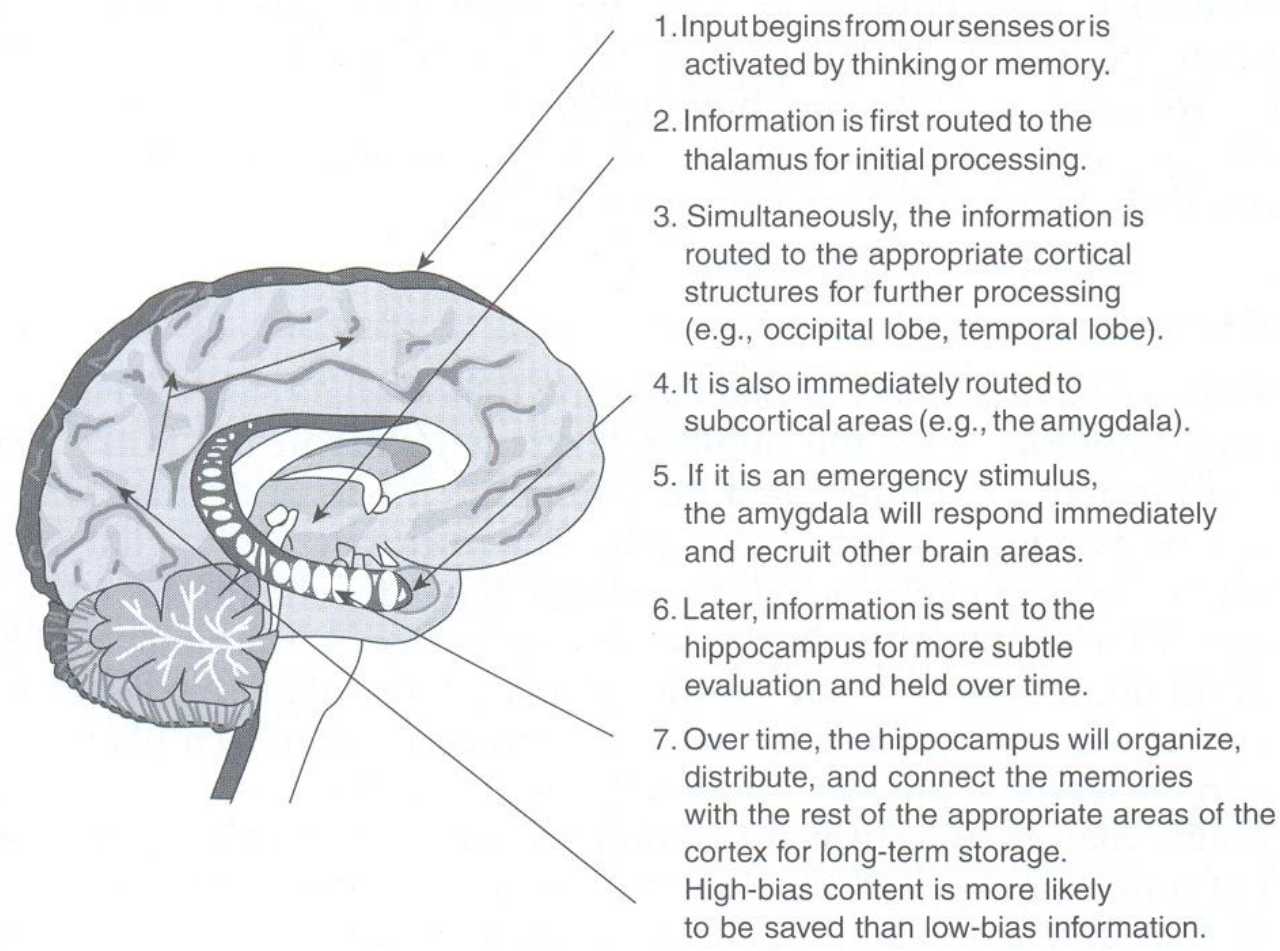

If the new learning is deemed important, it is organized and indexed by the hippocampus and later stored in the cortex. In fact, it will be stored in the same lobe that originally processed it - visual information in the occipital lobe, language in the temporal lobe, and so on. The original processing takes place at the lightning speed, but the subsequent stages and storage process can take hours, days, and even weeks (Jensen, 2008a, p. 10).

It is important to know that humans learn in many ways, including through sensitization, habituation, conditioned responses, semantic learning, imitation, and by doing. Many of these processes are not well understood. And although they may share parts of a pathway, we are each unique, and the different input is processed differently.

\section{Fundamental principles of brain-based learning}

The most important change for education is to understand how human beings learn and place that understanding at the very center of teaching. H. Schachl (2006, p. 7-9) summarized what we presently know about learning and compared to other branches of science, brain research and number of its findings may be well integrated into teaching and learning even now. He has compiled twelve credos to efficient and effective teaching and learning.

Credo 1: Overview before details

Before dealing with details, it is essential to provide an overview. It helps the brain to locate existing memory files and to create new ones. It will then be ready to take in all the details. It is essential to create and provide advance organizers. 


\section{Acta Technologica Dubnicae}

volume 2, 2012, issue 2

Credo 2: Clear teaching and learning aims

A clear answer to the learners' "Why?" makes it easier for them to see the relevance of a task. It has long been known that awareness of why one is doing something increases one's readiness to learn and makes for more perceptive learners.

\section{Credo 3: Arouse interest}

Keen interest is the best possible point of departure for taking in new things and committing them to memory. Interest generates a positive attitude, an essential precondition of efficient learning. Links to prior knowledge and to the learner's own experience(s) as well as new information presented in a captivating manner will increase the learner's interest.

\section{Credo 4: Revision and repetition}

"Repetitio est mater studiorum" (No studies without revision) are the words of the ancient Romans. The truth of this ancient adage is borne out by modern neuroscience: Repeated activation of neural circuits makes them more stable. Homework certainly makes sense, especially if it encourages revision of topics the learner has grasped already. Revision can come in various guises, and again the Romans had a word for it: "Variatio delectate" (Variety is the spice of life). Mechanical rote learning (without any cognitive engagement) is pointless.

\section{Credo 5: Multi-sensory approach}

Information should not only enter the brain via the learner's eyes and ears, but also via tactile stimuli. This produces multiple links, and hence a more permanent memory in the brain's circuitry. "Grasping" the meaning for something also implies doing it yourself and then explaining it to others, another efficacious way to learn.

\section{Credo 6: Affective factors}

Stress and anxiety block the paths of information into a person's memory. A long-term storage and swift retrieval of information require positive emotions. Their role in learning and in thought processes has been demonstrated both from an anatomical and a physiological point of view.

\section{Credo 7: Feedback}

Learning is pointless if there is no way to check whether the right things have been learnt. Brain research tells us that early feedback is of paramount importance. During the stage at which information is being stored in the neural circuits, "repairs" are easier to effect than after the process has been concluded. Invariably, unlearning is more arduous than learning new things. Such feedback can be provided by the learner's self-monitoring or assessment by others. When giving feedback, remember to praise, reinforce and confirm.

\section{Credo 8: Take breaks}

The chemical activities in the brain need time to process incoming information. This consolidation process should not be disrupted by the arrival of additional, possibly not wholly dissimilar information. Suggested activities during breaks can be a period of sleep, playing a game, listening to music, sports activities, etc. Preferably, such activities should involve physical exercise, and there should be no link between them and the work done beforehand. In order not to impair the process of consolidation it is essential to prevent any interference caused by kindred subject matter being presented nearly simultaneously. This will lead to confusion and the information cannot "sink in".

\section{Credo 9: Sequencing in teaching and learning}

A golden thread - a logical sequence of steps in learning - enables the brain to establish effective links between new and previous, related information, thus making it "meaningful" (cf. credo 10). Advance information also facilitates comprehension and makes learning less stressful. Items that resemble one another too closely should not be learned in a quick succession - interference and overlap might impair the learning process. 


\section{Acta Technologica Dubnicae \\ volume 2, 2012, issue 2}

\section{Credo 10: The importance of associative networks}

Numerous experiments in cognitive psychology have demonstrated that human memory functions as a network (associations, etc.). Like most things in nature, the "biological apparatus" called brain is extremely complex in its circuitry. Come to that, the whole world is a highly complex system of interconnected networks: Associative networks can be established by means of context-based learning, multi-sensory learning (credo 5), cross-curricular, and project-oriented learning.

\section{Credo 11: Specific aptitudes}

This point is more than a mere appendix. It is an important principle in neurodidactics. The task is to find out about a person's specific strengths and interests, to be able to promote and advance them better. Such an optimized use of educational resources on a national scale will also help to enhance a country's appeal as an industrial base. This eleventh principle also implies that learning disabilities can be dealt with more effectively by means of customized remedial teaching.

\section{Credo 12: Learning by imitation}

In the middle of the nineties the Italian researcher G. Rizzolatti (Iacobini, 2009, p. 66; Degen, 2007, p. 11-33) and his colleagues got a surprising, exciting result: If a monkey grasps a thing, the nerve cells of a specific region of the brain fire are in action. The same firing is, if someone plans this movement. The cells fire before doing it. But the surprising and most exciting finding is, thirdly, that in a small subset of this brain region the cells fire also when someone observes another person grasping. It is like a mirror in our brain, and therefore these specific cells are called "mirror neurons". Imitation is necessary and important. As a consequence, it is important to remember that it is necessary to demonstrate exactly and often. Teacher should set a good example and take care of good feelings of pupils.

Designing a quality learning experience for pupils is the very first step of effective teaching. These four principles (Armstrong, 2008, p. 30) of lesson design are important to consider prior to delivering instruction:

1. Identify the essential knowledge to be learned and method(s) of assessment and feedback.

2. Activate prior knowledge to build connections to new content.

3. Select a variety of strategies to engage all learners.

4. Teach bell-to-bell and provide closure.

The teacher's profession is not about filling up pupils with facts, but rather opening up pupils to lifelong learning. Start with the premise that your pupils can and will learn and learn. The structure of the lesson plan has more to do with its success than does its delivery.

\section{Conclusion}

Innovation appearing also in educational practice in Slovakia is represented by several terms such as neurodidactics, neuropedagogy, brain-compatible learning, and brain-based learning. It is a field that respects multidisciplinary approach. Neuroscience is a basis for this innovative point of view that is focusing not just on brain processes happening during learning, but also on lesson planning respecting and developing pupils' individuality. Brain-based learning is trying to implement the principles on the neuroscientific base and support creativity, use variable teaching methods, long-term memory strengthening, create enriched environment as well as relaxation and coping strategies. Learning involves changes in strength synapses, the connections between neurons in the gray matter. Based on the findings of brain research, the brain-based teaching provides principles and proposals for effective teaching and learning. The main goal of these principles is to intervene in pedagogical practice. Not all of them are brand new, but they confirm the theories and principles of progressive pedagogy and prove that they are effective. Therefore, an integration of brain-based learning in the teacher training would be desirable. 


\section{Literature}

ARMSTRONG, S.: Teaching smarter with the Brain in focus. Practical ways to apply the latest brain research to deepen comprehension, improve memory and motivate students to achieve. New York: Scholastic, 2008.

CAINE, R. - CAINE, G.: Making Connections: Teaching and the Human Brain. Alexandria: Association for Supervision and Curriculum Development, 1991.

CASPARY, R.: Lernen und Gehirn. Der Weg zu einer neuen Pädagogik. Freiburg: Herder, 2006.

DEGEN, R.: Nervenbrücke zwischen Du und Ich. In: Bild der Wissenschaft, 2007, n. 11, p. 30-33.

GARDNER, H.: Frames of Mind: The Theory of Multiple Intelligences. New York: Basic Books, 1983.

GARRETT, B.: Brain \& Behavior. An introduction to Biological Psychology. Canada: SAGE Publications, 2009.

HART, L.: Human Brain and Human Learning. New York: Longman, 1983.

HERRMANN, U.: Neurodidaktik. Grundlagen und Vorschläge für gehirngerechtes Lehren und Lernen. Weinheim: Beltz, 2006.

IACOBINI, M.: Die Gedanken der Anderen. In: Gehirn \& Geist, 2009, n. 11, p. 66.

JENSEN, E.: Brain-based learning. The new paradigm of teaching. Thousand Oaks, California: Corwin Press, 2008a.

JENSEN, E.: Teaching with the brain in mind. Alexandria: Association for Supervision and Curicculum Development, 2008b.

PREISS, G.: Neurodidaktik. Theoretische und praktische Beiträge. Herbolzheim: Centaurus, 1998.

SCHACHL, H.: Was haben wir im Kopf. Linz: Veritas-Verlag, 2006.

SLAVKIN, M. L.: Authenic learning. Toronto: Scarecrow Education, 2004.

SPITZER, M.: Das Gehirn. Eine Gebrauchsanleitung. Reinbek: Rowohlt, 2006.

TOKUHAMA-ESPINOSA, T.: Why Mind, Brain, and Education Sciences the "New Brain-Based" Education, 2010. [online]. [cit. 2011. 04. 04].

http://education.jhu.edu/newhorizons/Journals/Winter2011/Tokuhama1 